\title{
Estimation of Body Fatness by Air Displacement Plethysmography in African American and White Children
}

\author{
JENNIFER C. NICHOLSON, JENNIFER R. McDUFFIE, SANDRA H. BONAT, \\ DESEREA L. RUSSELL, KRISTIE A. BOYCE, SERENA McCANN, MADELINE MICHAEL, \\ NANCY G. SEBRING, JAMES C. REYNOLDS, AND JACK A. YANOVSKI
}

Unit on Growth and Obesity, National Institute of Child Health and Human Development [J.C.N., J.R.M., S.H.B., D.L.R., K.A.B., S.M., J.A.Y.]; Division of Nutrition Research Coordination [S.M.]; and Nutrition Department [M.M., N.G.S.] and Nuclear Medicine [J.C.R.], Warren Grant Magnuson Clinical Center, National Institutes of Health, Bethesda, MD 20892, U.S.A.

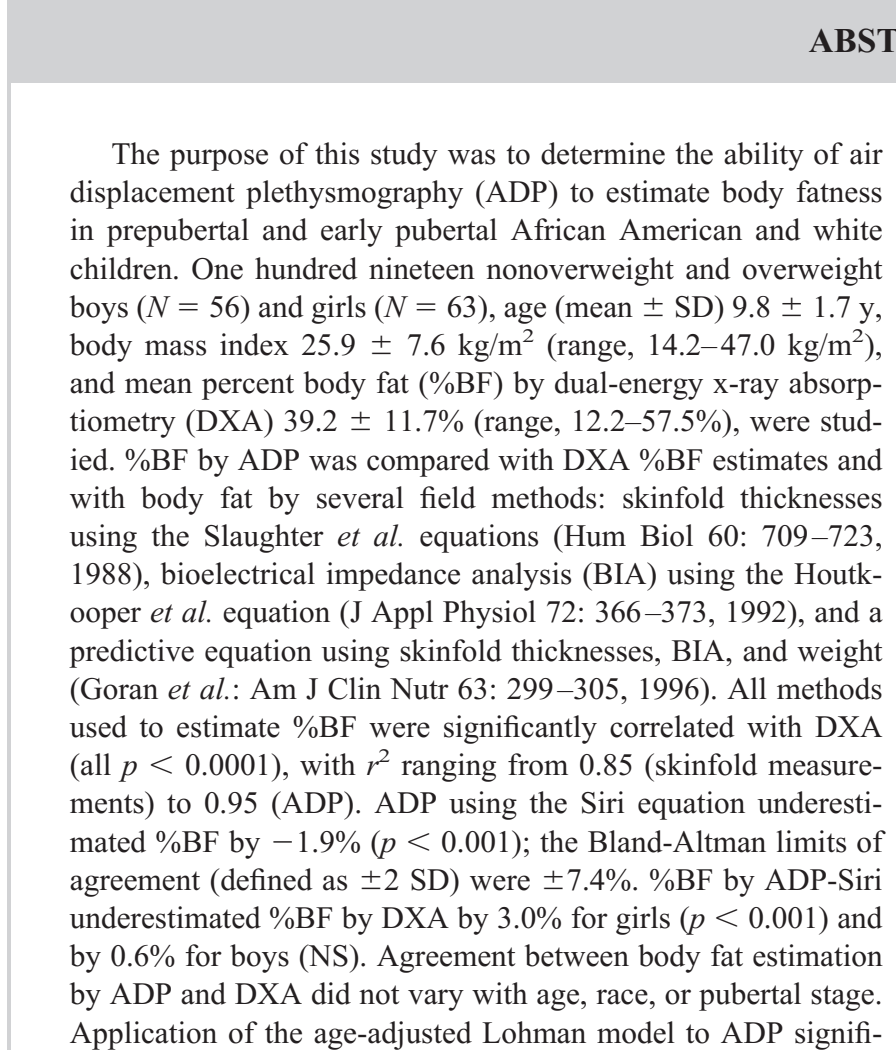

cantly increased the magnitude of the underestimation to $-6.9 \%$ $(p<0.0001)$. Prediction of \%BF by the Slaughter skinfold thickness equation showed no significant mean bias for the overall data, but significantly underestimated $\% \mathrm{BF}$ in girls $(-3.7 \%)$ while overestimating $\% \mathrm{BF}$ in boys $(+2.4 \%)$ with wide limits of agreement $( \pm 17.7 \%, p<0.01$ versus $\mathrm{ADP}) . \% \mathrm{BF}$ by the Houtkooper BIA equation or Goran model underestimated $\% \mathrm{BF}$ to a significantly greater degree than ADP (Houtkooper, $-8.1 \%$; Goran, $-10.1 \%$; both $p<0.0001$ versus DXA or ADP). Determination of \%BF from ADP using the Siri model slightly underestimates $\% \mathrm{BF}$ as determined by DXA in girls, but appears to be superior to existing field methods both in accuracy and limits of agreement. Because of the ease with which it can be performed, ADP may prove useful for investigations of adiposity in children. (Pediatr Res 50: 467-473, 2001)
DXA, dual-energy x-ray absorptiometry
ADP, air displacement plethysmography
BIA, bioelectrical impedance analysis
$\% \mathbf{B F}$, percent body fat
$\mathbf{V}_{\text {TG }}$, thoracic gas volume
FFM, fat-free mass

Excessive body weight has become increasingly common among children in the United States (1). The prevalence of overweight in children and adolescents has almost doubled

Received January 5, 2001; accepted May 4, 2001.

Correspondence and reprint requests: Jack A. Yanovski, M.D., Ph.D., Unit on Growth and Obesity, DEB, NICHD, NIH, 10 Center Drive, Building 10, Room 10N262 MSC 1862, Bethesda, MD 20892-1862; e-mail JY15i@NIH.GOV

Supported by Z-01-HD-04-00641 (J.A.Y.) and the Office of Research on Minority Health

J. Yanovski, M. Michael, and N. Sebring are Commissioned Officers in the United States Public Health Service. during the past two decades, and is now approximately $14 \%$ of young children and $12 \%$ of adolescents $(2,3)$.

Accurate assessment of body composition, particularly body fatness, is a key component for both research about and clinical treatment of childhood obesity. Assessing body fatness and changes in body adiposity while children are growing can be difficult, because of the confounding effects of growth on lean and fat mass. Several different methods for estimation of body fat mass have been developed that depend on measurements of total body water, total body potassium, $\mathrm{x}$-ray absorption, electrical conductance, body density, skinfold thicknesses, or other 
anthropometric and demographic variables (4). Each methodology has advantages and disadvantages based on ease of use, equipment requirements, inconvenience or risk to children, accuracy, and reliability.

None of the predictive equations based on simple methods, such as skinfold thickness measurements or BIA, has so far been shown to have sufficient precision or accuracy to replace the more cumbersome and less available approaches to pediatric body composition analysis. The gold standard for estimation of body fatness has traditionally been determination of body density by underwater weighing. This technique requires the subject to exhale maximally to residual lung volume and then be submerged underwater. This method poses issues of compliance and performance, especially for pediatric populations. DXA is a method that measures fat mass reliably and has been suggested for use as a reference method (5). It has been shown to be highly accurate and reproducible (6), but requires radiation exposure. Both underwater weighing and DXA are time-consuming, costly, and not available in many settings. Other accurate methods, such as potassium counting or estimation of total body water by isotope dilution, suffer from these same difficulties.

A more recent method for body density measurement that may overcome some of these limitations is ADP. In adults, ADP appears to be a method with good precision and accuracy (7), with several studies suggesting that $\% \mathrm{BF}$ determined by ADP is comparable to that found by underwater weighing (8, 9). A few children have also been studied with ADP (10-12, 34), but insufficient numbers of preadolescents have been examined to determine reliably the utility of ADP for measurements of body fat. There are also few data examining whether ADP can estimate body fat accurately in groups known to differ in body composition, such as African American and white children (13-16).

We therefore examined ADP-derived estimates of body fatness in both nonoverweight and overweight African Amer- ican and white boys and girls. Body fat by ADP was compared with DXA body fat estimates and with body fat by several field methods: skinfold thicknesses, BIA, and a predictive equation using skinfold thicknesses, BIA, and weight that was derived in relation to DXA (17).

\section{METHODS}

Subjects. We recruited 119 healthy African American and white subjects ( 63 girls and 56 boys, Table 1) through notices mailed to appropriate-aged children in the Montgomery County, MD, U.S.A., Prince Georges County, MD, U.S.A., Fairfax County, VA, U.S.A., and Washington, DC, U.S.A., school systems, by advertisements in local newspapers, and in the case of overweight children, by referral from local physicians for studies of physiology and metabolism. Subjects were considered overweight if their body mass index exceeded the 85th percentile [determined by NHANES I age-, sex-, and race-specific data; (18)]. Subjects were considered not overweight if body mass index (adjusted for age, sex, and race) was between the 5th and 85th percentiles. All subjects had normal physical examinations and normal hepatic, renal, and thyroid function. Each subject underwent a detailed medical history, and was examined for clinical signs of adrenarche or gonadarche. The study was approved by the National Institutes of Child Health and Human Development Institutional Review Board. Each child gave written assent, and a parent gave written consent, for protocol participation.

ADP. Subjects were studied in the morning, after an overnight fast. Subjects were instructed to void before measurements were obtained. Body density by ADP was assessed using the BOD POD air displacement body composition system (Life Measurement Instruments, Concord, CA, U.S.A.; software version 1.69), according to the manufacturer's directions and procedures previously described (7). Subjects were assessed in minimal clothing (either underwear or a tight-fitting bathing

Table 1. Clinical characteristics*

\begin{tabular}{|c|c|c|}
\hline Characteristic & Girls $(n=63)$ & Boys $(n=56)$ \\
\hline Age (y) & $9.7 \pm 1.5(6.1-14.0)$ & $9.8 \pm 1.9(6.1-14.0)$ \\
\hline Race & $29 \mathrm{AA}, 34 \mathrm{~W}$ & $13 \mathrm{AA}, 43 \mathrm{~W}$ \\
\hline Weight $(\mathrm{kg})$ & $55.5 \pm 19.2(21.3-100.6)$ & $57.0 \pm 27.3(20.5-127.3)$ \\
\hline BMI $\left(\mathrm{kg} / \mathrm{m}^{2}\right)$ & $25.6 \pm 6.0(15.3-37.9)$ & $26.3 \pm 9.1(14.2-47.0)$ \\
\hline $\mathrm{DXA} \% \mathrm{BF}$ & $40.8 \pm 9.3(18.3-55.5)$ & $37.0 \pm 13.7(12.2-57.5)$ \\
\hline Boy's testis volume (mL) & & $2.6 \pm 1.5(1.0-8.0)$ \\
\hline II & $17(27.0 \%)$ & $14(25.5 \%)$ \\
\hline III & $17(27.0 \%)$ & $7(12.8 \%)$ \\
\hline IV & $4(6.3 \%)$ & $1(1.8 \%)$ \\
\hline $\mathrm{V}$ & $2(3.2 \%)$ & 0 \\
\hline \multicolumn{3}{|l|}{ Girl's breast stage (\%) } \\
\hline I & $10(15.9 \%)$ & \\
\hline
\end{tabular}

* For pubic hair and breast Tanner stage, raw number of subjects and (percentage) are given. Mean \pm SD and (range) are given unless otherwise indicated. Abbreviations: AA, African American; W, white. 
suit) and wearing a swim cap. Total body volume was measured while subjects sat comfortably in the ADP chamber. $\mathrm{V}_{\mathrm{TG}}$ was measured during tidal breathing and during exhalation against a mechanical obstruction. The detailed procedure has been described elsewhere, and usually takes $<10 \mathrm{~min}$ to complete (7). Each subject practiced "panting like a dog" against a closed breathing tube three times before $V_{T G}$ was measured. Some subjects required several attempts before $V_{T G}$ could be determined. In subjects who were unable to perform the test of $\mathrm{V}_{\mathrm{TG}}$ adequately $(n=10)$, a prediction of $\mathrm{V}_{\mathrm{TG}}$ based on age, sex, and height was used. There were no systematic differences between results using predicted $\mathrm{V}_{\mathrm{TG}}$ and those with measured $\mathrm{V}_{\mathrm{TG}}$ (data not shown). Body density is then calculated as body mass divided by (total body volume $+0.40 \times$ $\mathrm{V}_{\mathrm{TG}}$ - surface area artifact). The surface area artifact is calculated by the supplied software and is used to account for changes in air temperature near the subject's body surface. In our laboratory, interassay coefficient of variation of ADP fat mass is $<8 \%$.

The two-compartment model most commonly used to estimate body fatness from body density is the equation of Siri (19). This estimation assumes a constant density of the FFM. However, the water content of FFM, which is the major influence on its density, has been reported to change during childhood and adolescence $(20,21)$, and an age-specific modification to the Siri equation has been suggested by Lohman $(22,23)$. Therefore, we determined body fat from ADP density using both the Siri equation (ADP-Siri) (19) and Lohman's age-adjusted equations $(22,23)$.

Measurement of body composition by DXA. Body composition was assessed by DXA using the Hologic QDR-2000 machine (Hologic, Waltham, MA, U.S.A.) in the pencil beam mode as previously described (13). DXA estimates of body fat were used as the criterion method to which all other estimates were compared. DXA fat mass measurements have previously been found to have excellent reproducibility in children $(r>$ 0.96; interassay coefficient of variation, $<6 \%$ ) (24), and a growing body of evidence indicates that DXA is an accurate method of quantifying fatness in small animals (25), children (26-28), and obese adults (29).

Anthropometric measurements for body composition. Skinfold thickness was measured by experienced dietitians as recommended (30) using Lange calipers (Cambridge Science Industries, Cambridge, MA, U.S.A.). All anthropometry was performed by one of three trained dietitians. Skinfold measurements, recorded to the nearest $0.5 \mathrm{~mm}$, were taken in triplicate at each site, and the average was used for analysis. Percent fat was calculated using the equations of Slaughter et al. (31) from triceps and subscapular measurements. Height (measured three times) was obtained using a stadiometer (Holtain Ltd., Crymych, Wales) that was calibrated to the nearest $1 \mathrm{~mm}$ before each subject's height was measured. Weight was obtained to the nearest $0.1 \mathrm{~kg}$ using a calibrated digital scale (Scale-Tronix, Wheaton, IL, U.S.A.).

$\boldsymbol{B I} \boldsymbol{A}$. Resistance and reactance were measured using one of two single-frequency BIA analyzers (models 101Q and 106, RJL Systems, Detroit, MI, U.S.A.) as recommended by the manufacturer. These units yield identical resistance and reac- tance readings (personal communication, Rudolph J. Liedtke, president, RJL Systems, Inc). Subjects removed socks, shoes, and any nearby metal jewelry before measurement. Source electrodes were placed on the posterior surface of the right hand between the proximal interphalangeal joint and the distal end of the third metacarpal and on the anterior surface of the right foot at the distal end of the second metatarsal, and were $\geq 5 \mathrm{~cm}$ distal to the receiving electrodes, which were placed between the styloid processes of the radius and ulna and between the medial and lateral malleoli of the ankle. Subjects were measured while lying supine on a nonconductive surface after a 3- to 5-min rest. Bioelectric resistance was measured after induction of a $50-\mathrm{kHz}$ electrical signal with a maximum current of either $500 \mu \mathrm{A}$ (model 101Q) or $800 \mu \mathrm{A}$ (model 106). FFM was calculated using the equations of Houtkooper et al. (32), and fat mass was determined by subtracting FFM from total body mass.

Predictive equation of Goran et al. We also examined the utility of an equation incorporating skinfold thickness, BIA, and weight, developed using DXA as a criterion, that has been suggested as a more accurate way to predict $\% \mathrm{BF}$ than the technique using either BIA or skinfold thickness alone (17). The equation is as follows:

$$
\begin{aligned}
& \operatorname{FFM}(\mathrm{kg})=\left[0.16 \times\left(H^{2} / R\right)\right]+(0.67 \times \text { weight })-(0.11 \\
& \times \text { triceps })-(0.16 \times \text { subscapular })+(0.43 \times \text { sex })+2.41 \mathrm{~kg}
\end{aligned}
$$

where $H$ is height and $R$ is bioelectric resistance.

Statistical analysis. Parametric data were analyzed on a Macintosh PowerPC using StatView 5.01 software (Abacus Concepts, Inc., Berkeley, CA, U.S.A.). Methods used to assess agreement were Bland-Altman pair-wise comparisons (33), simple regression, and ANOVA with repeated measures using race, sex, and pubertal maturation as between-groups factors. The $95 \%$ confidence intervals for the Bland-Altman limits of agreement were also calculated. Significant ANOVAs were followed by paired $t$ tests to assess differences in bias. All tests were two-tailed. Twenty subjects did not undergo anthropometric measurements or BIA contemporaneously with the other measures, and were therefore excluded from the analyses of these measurements. Variables compared were \%BF obtained from DXA (software version 5.64), application of the Siri equation and the age-adjusted Lohman equation to ADP body density measurements, the Slaughter et al. age- and race-specific equations derived from triceps and subscapular skinfold measurements, the Houtkooper et al. BIA equations (by subtracting the FFM as determined by BIA from total body weight, and dividing by body weight), and the Goran et al. predictive equation that uses both BIA and skinfold thickness.

\section{RESULTS}

Subjects' clinical characteristics are shown in Table 1. The sample included a wide range of body fatness as estimated by DXA. There were no differences in age, weight, height, body mass index, and \%BF by DXA between boys and girls.

All of the methods used to estimate $\% \mathrm{BF}$ were significantly correlated with DXA (all $p<0.0001$ ). The $r^{2}$ ranged from 0.85 (Slaughter skinfold measurements) to 0.95 (ADP-Siri). 
Table 2. Mean differences and limits of agreement for $\% B F$ estimates relative to $D X A \% B F$

\begin{tabular}{lccc}
\hline \multicolumn{1}{c}{$\%$ BF } & & & \\
estimated by & All subjects & Girls & Boys \\
\hline ADP-Siri & $-1.9 \pm 7.4^{*}$ & $-3.0 \pm 6.9^{*}$ & $-0.6 \pm 7.1$ \\
ADP-Lohman & $-6.9 \pm 8.1^{* \dagger}$ & $-8.5 \pm 7.8^{* \dagger}$ & $-5.1 \pm 6.8^{*}$ \\
Slaughter & $-0.8 \pm 17.7$ & $-3.7 \pm 13.6^{*}$ & $2.4 \pm 19.6$ \\
Houtkooper & $-8.1 \pm 9.0^{* \dagger}$ & $-8.8 \pm 8.3^{* \dagger}$ & $-7.4 \pm 9.6^{* \dagger}$ \\
Goran & $-10.1 \pm 12.4^{* \dagger}$ & $-10.8 \pm 11.0^{* \dagger}$ & $-9.2 \pm 13.8^{*} \dagger$ \\
\hline
\end{tabular}

Values are given as mean $\pm 2 \mathrm{SD}$.

$* P<0.001$, mean difference significantly different compared with 0 .

$\dagger p<0.001$, mean differences were significantly different compared with mean difference of ADP-Siri.

Bland-Altman comparisons of ADP against DXA are shown in Figure 1 and summarized in Table 2. When all subjects were analyzed as one group, ADP-Siri (Fig. $1 A$ ) underestimated the $\%$ BF by $-1.9 \%(p<0.001)$; the limits of agreement (defined by Bland and Altman as $\pm 2 \mathrm{SD}$ ) were $\pm 7.4 \%$. Application of the age-adjusted Lohman model (Fig. $1 B$ ) significantly increased the magnitude of the underestimation to $-6.9 \%(p<$ $0.0001)$; the limits of agreement with DXA were not significantly different from that of ADP-Siri. Therefore the \%BF estimates obtained by application of the Siri equation to ADP density measurements were used in all further analyses. Neither ADP method demonstrated a significant correlation between measurement error and \%BF.

The bias of body fat estimation by ADP-Siri was significantly different from 0 only for girls (Table 2, Fig. 2). $\% \mathrm{BF}$ was underestimated by ADP-Siri by $3.0 \%$ for girls $(p<0.001)$ and by $0.6 \%$ for boys (NS). Agreement between body fat estimation by ADP and DXA did not vary with age (Fig. 3) or with race (Fig. 4), breast or pubic hair Tanner stage, or testis size (data not shown).

Bland-Altman comparisons of field methods for estimation of body fat against DXA are shown in Figure 5 and summarized in Table 2. Prediction of \%BF by the Slaughter et al. skinfold thickness equations (Fig. 5A) showed no significant mean bias for the overall data, but significantly underestimated $\% \mathrm{BF}$ in girls by $3.7 \%(p<0.003)$ and showed a nonsignificant trend to overestimate $\% \mathrm{BF}$ in boys $(+2.4 \%, p=0.09)$. Com- pared with ADP-Siri, the SD of measurements was much broader for the Slaughter et al. model; the upper bound for the limit of agreement between the Slaughter et al. model and DXA was significantly greater than the upper limit of agreement between ADP-Siri and DXA for the overall data $(+17.7$ versus $+7.4, p<0.01)$, as well as for both the boy $(+19.6$ versus $+7.1, p=0.025)$ and girl $(+13.6$ versus $+6.9, p=$ $0.025)$ subgroups. BIA using the Houtkooper et al. equation significantly underestimated $\% \mathrm{BF}$ by $8.1 \%$ (Fig. $5 B$ ); this underestimation was significantly greater than that of the ADPSiri method $(p<0.0001)$. The Goran model also underestimated \%BF (Fig. $5 C$ ) to a significantly greater degree than ADP-Siri $(-10.1 \%$ versus $-1.9 \%, p<0.0001)$. Each of the three field methods shown in Figure 5 also had a significant positive relationship $(p<0.01)$ between error of body fat measurement and amount of body fat.

\section{DISCUSSION}

We examined the ability of ADP to estimate percent body fat in both nonoverweight and overweight African American and white boys and girls, using DXA as the criterion method. Two different two-compartment models, the Siri equation and Lohman's age-adjusted equation, were used to determine $\% \mathrm{BF}$ from ADP-measured body density, and the results of each were compared. Both methods were found to underestimate $\% \mathrm{BF}$ by a small but significant amount, with the Siri estimates of $\% \mathrm{BF}$ agreeing better with DXA than the age-adjusted Lohman model.

The accuracy, compared with DXA, of several other field methods for evaluation of body composition was also compared with that of ADP. Determination of \%BF by skinfold thickness using the model of Slaughter et al. (31) had the smallest mean bias, with bias for both boys and girls less than $\pm 4 \%$. However, the limits of agreement of this technique with DXA were surprisingly broad. \%BF was under- or overestimated by $>10 \%$ in $>24 \%$ of subjects by the Slaughter et al. model, whereas $<2 \%$ of measurements by ADP-Siri were as discordant. Both the Houtkooper BIA equation and the Goran model significantly underestimated $\% \mathrm{BF}$, with wide limits of
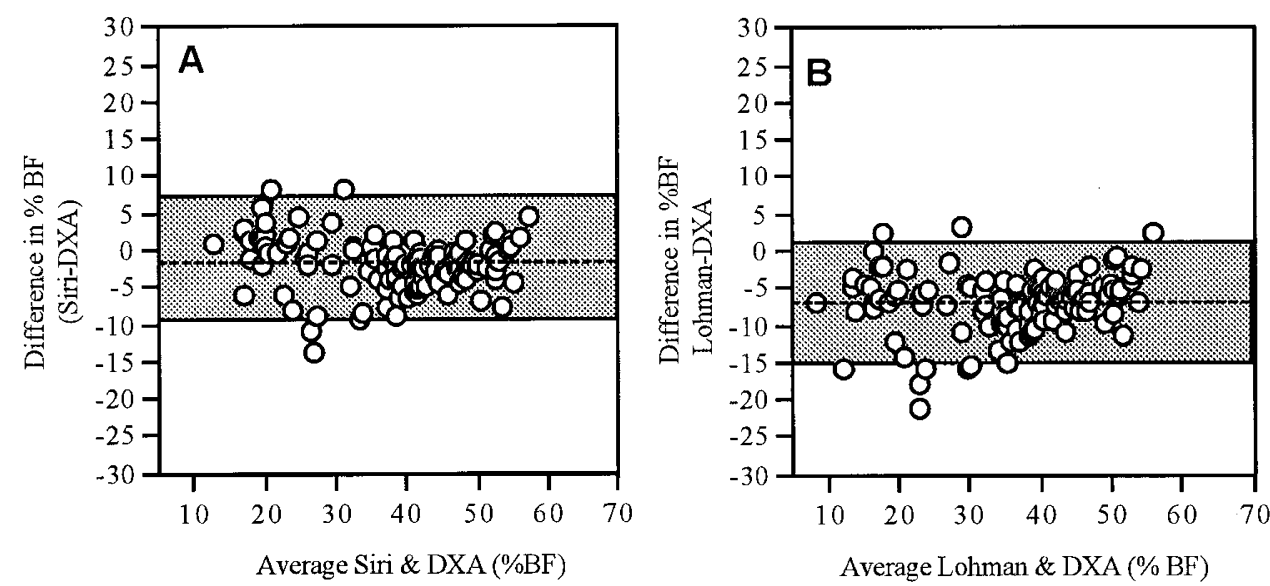

Figure 1. Bland-Altman plots of bias in \%BF estimation using DXA as the criterion method for: ADP using the Siri model $(A)$; ADP using the Lohman age-adjusted model $(B)$. Dashed lines, mean difference; shaded area, \pm 2 SD of mean difference. 


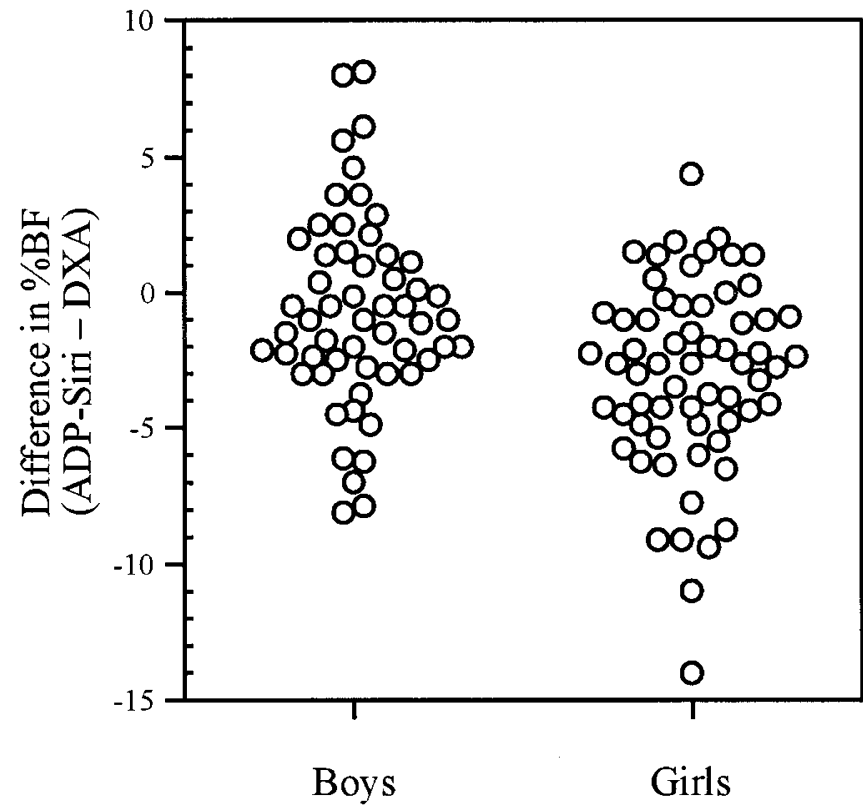

Figure 2. Scatterplot of the difference in $\% \mathrm{BF}$ as measured by ADP-Siri and DXA in boys compared with girls.

agreement and a tendency for underestimation to increase as body fat increases. Indeed, there were significant relationships between measurement error and \%BF for each field method. Thus, although the Slaughter et al. method appears to have the least systematic bias of available field methods, none of these methods can be recommended for use. Determination of \%BF from ADP using the Siri model thus appears to be superior to existing field methods. In support of this finding, Fields and Goran (34) recently studied 25 children and found body fat estimates by ADP to have no significant bias compared with a four-compartment model currently believed to be superior to DXA.

We found no racial or age-related differences in the estimation of $\% \mathrm{BF}$ by $\mathrm{ADP}$; however, we did find a disparity related to sex. ADP significantly underestimated $\% \mathrm{BF}$ in girls by $-3.0 \%$, but appeared to have no systematic bias for $\% \mathrm{BF}$ estimation in boys. The reason for this disparity is not clear; there were no differences in age, height, weight, body mass index, or DXA-determined \%BF between the two populations. Among previous studies of the ADP technique, only one small adult study found a significant sex difference. Levenhagen et al. (9) found that women had a higher $\% \mathrm{BF}$ and men had a lower $\% \mathrm{BF}$ in comparison with that determined by underwater weighing. A possible explanation for the underestimation of $\% \mathrm{BF}$ of girls found in our study may be technique-related. When subjects are studied by ADP, clothing can decrease measured body volume, and thereby increase body density estimates $(7,35)$. This issue is minimized by having the subject wear as little clothing as possible. In our study, girls typically wore a one-piece bathing suit and boys wore underpants but no undershirt. The bathing suits worn by girls thus generally covered more surface area, which could lead to somewhat greater error in volume measurements. Underestimation of volume would lead to overestimation of density, and thus an underestimation of $\% \mathrm{BF}$.

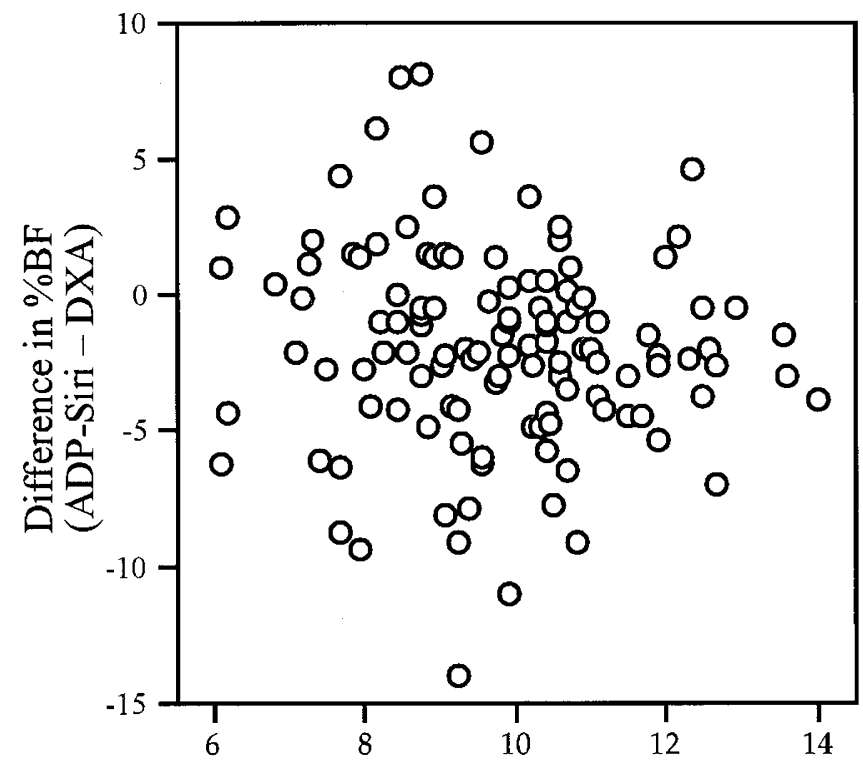

Age (years)

Figure 3. Scatterplot of the difference in $\% \mathrm{BF}$ as measured by ADP-Siri and DXA plotted against age of subject.

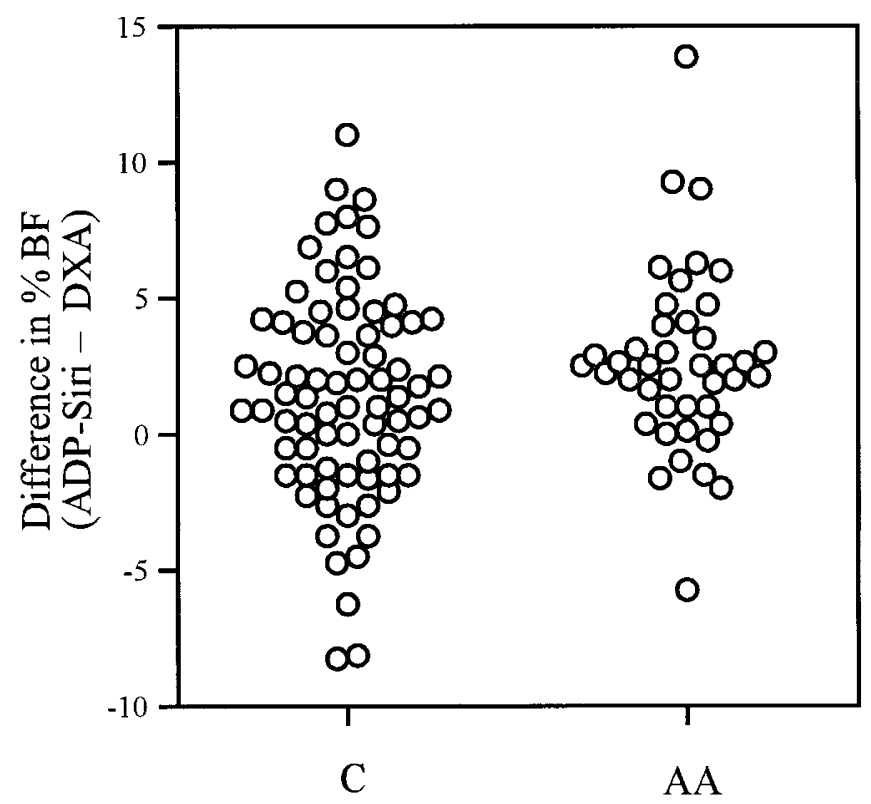

Figure 4. Scatterplot of the difference in $\% \mathrm{BF}$ as measured by ADP-Siri and DXA in African Americans $(A A)$ compared with whites $(C)$.

ADP measurement of body composition requires the determination of the amount of air in the lungs during normal tidal breathing, or the average $\mathrm{V}_{\mathrm{TG}}$. The ADP apparatus used in this study is capable of measuring $\mathrm{V}_{\mathrm{TG}}$, as described above. However, a few subjects may have difficulty performing the test of $\mathrm{V}_{\mathrm{TG}}$ adequately; in this case, ADP can provide a predicted $\mathrm{V}_{\mathrm{TG}}$. A study by McCrory et al. (36) found that predicted and measured $\mathrm{V}_{\mathrm{TG}}$ did not differ significantly in adults; as a result there were no significant differences in $\% \mathrm{BF}$ when either value was used. Similarly, we found that there were no systematic differences between results using predicted $\mathrm{V}_{\mathrm{TG}}$ for the 10 


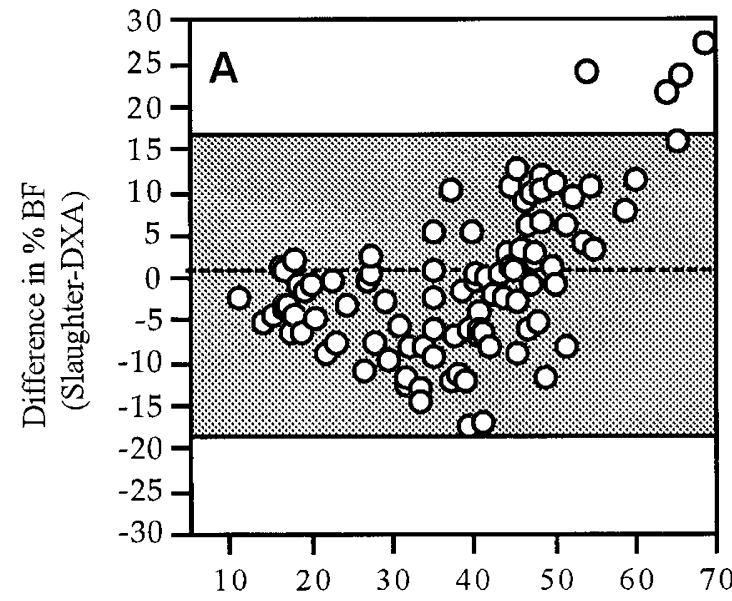

Average Slaughter \& DXA (\% BF)

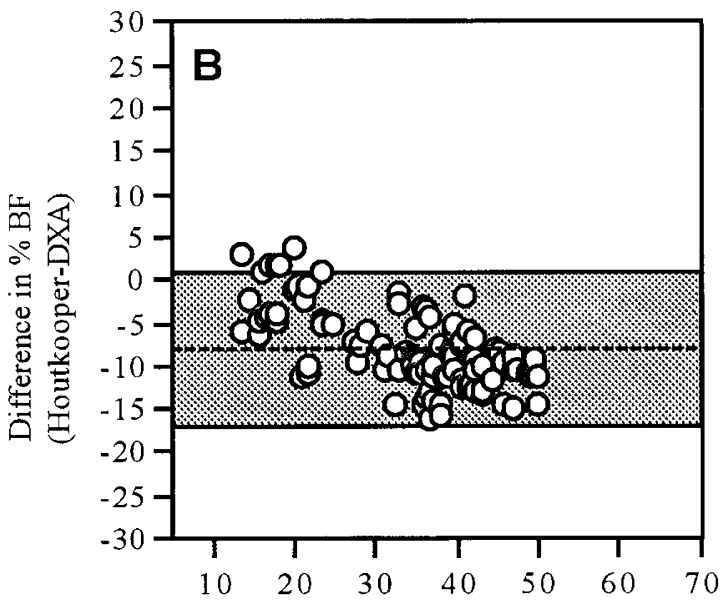

Average Houtkooper \& DXA (\%BF)

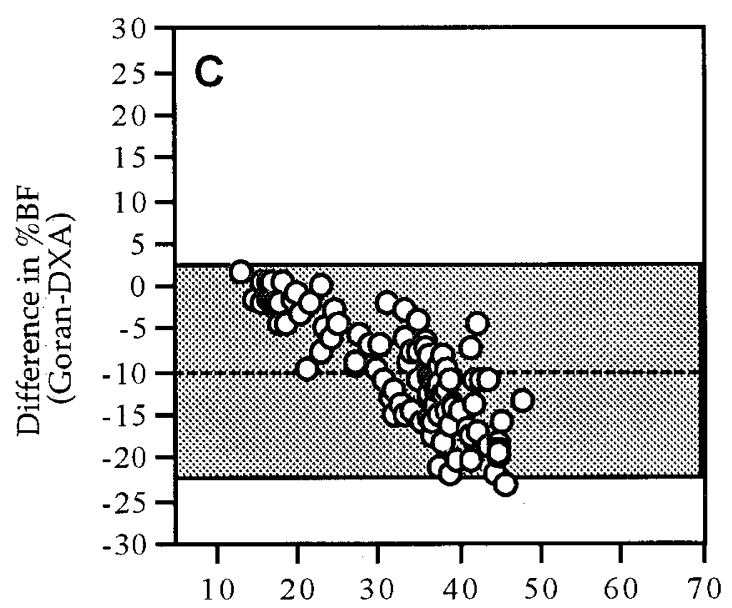

Average Goran \& DXA (\%BF)

Figure 5. Bland-Altman plots of bias in $\% \mathrm{BF}$ estimation using DXA as the criterion method for skinfold measurements using the Slaughter et al. equations $(A)$; BIA using the Houtkooper et al. equation $(B)$; and the Goran model of BIA and anthropometric measurements $(C)$. Dashed lines, mean difference; shaded area, $\pm 2 \mathrm{SD}$ of mean difference.

subjects who were unable to give an adequate test and those with measured $\mathrm{V}_{\mathrm{TG}}$ only (data not shown).

In this study, density measurements obtained from ADP using the Siri equation led to estimates of $\% \mathrm{BF}$ that agreed better with DXA than the age-adjusted Lohman model. This result is not completely consistent with the findings of Roemmich et al. (37). In a study of a smaller number of older children, Roemmich et al. (37) compared \%BF estimates from density determined by underwater weighing and from DXA with those of a four-compartment criterion method, and found that both DXA and the Siri two-compartment model overestimated $\% \mathrm{BF}$ (relative to the four-compartment model), but that the Siri model had even greater overestimates than DXA. In this study, the Lohman age-adjusted model reduced the overpredictions of the Siri model so that the Lohman model estimates became similar to those of DXA. The reason why results of the current study differ from the results of Roemmich et al. (37) are not clear, but may have to do with differences in subject age and race, and with the different criterion method used (DXA). Although DXA has been shown to have excellent concordance with criterion methods of body composition in normal weight children (26-28) and obese adults (29), data demonstrating the accuracy of DXA body fat measurements in obese children do not as yet exist. Thus, further studies are needed to determine whether the Lohman age adjustments should be applied to correct $\% \mathrm{BF}$ measurements obtained from ADP.

Currently accepted gold standard techniques of body composition measurement have many methodological considerations that limit their usefulness. Underwater weighing is time-consuming, requires a lifeguard to be present, and is considered difficult or uncomfortable by subjects. DXA, although not difficult for most subjects, involves radiation exposure and requires costly equipment that may not be available in all settings. In contrast, ADP is fairly easy for both subject and technician to perform, generally takes $<15$ min to complete, and is without risk or discomfort to the subject.

We conclude that in 6- to 14-y-old children, measurements of body fat calculated from application of the Siri equation to ADP density measurements are equivalent to those obtained by DXA in boys, and underestimate the body fat of girls by a small but significant amount. ADP is superior to available field methods both in its accuracy and limits of agreement, and because of the ease and speed with which it can be performed, may prove useful for investigations of adiposity in children.

\section{REFERENCES}

1. Troiano RP, Flegal KM 1998 Overweight children and adolescents: description, epidemiology, and demographics. Pediatrics 101:497-504

2. [No authors listed] 1997 Update: prevalence of overweight among children, adolescents, and adults - United States, 1988-1994. MMWR Morb Mortal Wkly Rep 46:198-202

3. Freedman DS, Srinivasan SR, Valdez RA, Williamson DF, Berenson GS 1997 Secular increases in relative weight and adiposity among children over two decades: the Bogalusa Heart Study. Pediatrics 99:420-426

4. Roche AF 1993 Methodological considerations in the assessment of childhood obesity. Ann NY Acad Sci 699:6-17

5. Van den Broeck J, Wit JM 1997 Anthropometry and body composition in children. Horm Res 48:33-42

6. Lohman TG, Harris M, Teixeira PJ, Weiss L 2000 Assessing body composition and changes in body composition. Another look at dual-energy x-ray absorptiometry. Ann NY Acad Sci 904:45-54

7. Dempster P, Aitkens S 1995 A new air displacement method for the determination of human body composition. Med Sci Sports Exerc 27:1692-1697

8. McCrory MA, Gomez TD, Bernauer EM, Mole PA 1995 Evaluation of a new air displacement plethysmograph for measuring human body composition. Med Sci Sports Exerc 27:1686-1691 
9. Levenhagen DK, Borel MJ, Welch DC, Piasecki JH, Piasecki DP, Chen KY, Flakoll PJ 1999 A comparison of air displacement plethysmography with three other techniques to determine body fat in healthy adults. J Parenter Enteral Nutr 23:293-299

10. Dewit O, Fuller NJ, Fewtrell MS, Elia M, Wells JC 2000 Whole body air displacement plethysmography compared with hydrodensitometry for body composition analysis. Arch Dis Child 82:159-164

11. Nunez C, Kovera AJ, Pietrobelli A, Heshka S, Horlick M, Kehayias JJ, Wang Z Heymsfield SB 1999 Body composition in children and adults by air displacement plethysmography. Eur J Clin Nutr 53:382-387

12. Lockner DW, Heyward VH, Baumgartner RN, Jenkins KA 2000 Comparison of air-displacement plethysmography, hydrodensitometry, and dual x-ray absorptiometry for assessing body composition of children 10 to 18 years of age. Ann NY Acad Sci 904:72-78

13. Yanovski JA, Yanovski SZ, Filmer KM, Hubbard VS, Avila N, Lewis B, Reynolds JC, Flood M 1996 Differences in body composition of black and white girls. Am J Clin Nutr 64:833-839

14. [No authors listed] 1992 Obesity and cardiovascular disease risk factors in black and white girls: the NHLBI Growth and Health Study. Am J Public Health 82:1613-1620

15. Morrison JA, Barton B, Biro FM, Sprecher DL, Falkner F, Obarzanek E 1994 Sexual maturation and obesity in 9- and 10-year-old black and white girls: the National Heart, Lung, and Blood Institute Growth and Health Study. J Pediatr 124:889-895

16. Meuller EH 1987 Ethnic differences in fat distribution during growth. In: Bouchard C, Johnston FE (eds) Fat Distribution During Growth and Later Health Outcomes. Alan R. Liss, New York, pp 127-145

17. Goran MI, Driscoll P, Johnson R, Nagy TR, Hunter G 1996 Cross-calibration of body-composition techniques against dual-energy $\mathrm{x}$-ray absorptiometry in young children. Am J Clin Nutr 63:299-305

18. Must A, Dallal GE, Dietz WH 1991 Reference data for obesity: 85th and 95th percentiles of body mass index $\left(\mathrm{wt} / \mathrm{ht}^{2}\right)$ and triceps skinfold thickness [published erratum appears in Am J Clin Nutr 1991;54:773]. Am J Clin Nutr 53:839-846

19. Siri WE 1961 Body composition from fluid spaces and density: analysis of methods. In: Brozek J, Henschel A (eds) Techniques for Measuring Body Composition. National Academy of Sciences/National Research Council, Washington, DC, pp 223-224

20. Boileau RA, Lohman TG, Slaughter MH, Ball TE, Going SB, Hendrix MK 1984 Hydration of the fat-free body in children during maturation. Hum Biol 56:651-666

21. Hewitt MJ, Going SB, Williams DP, Lohman TG 1993 Hydration of the fat-free body mass in children and adults: implication for body composition assessment. Am J Physiol 265:E88-E95

22. Lohman TG 1986 Applicability of body composition techniques and constants for children and youths. Exerc Sport Sci Rev 14:325-357
23. Lohman TG 1989 Assessment of body composition in children. Pediatr Exerc Sci $1: 19-30$

24. Figueroa-Colon R, Mayo MS, Treuth MS, Aldridge RA, Weinsier RL 1998 Reproducibility of dual-energy x-ray absorptiometry measurements in prepubertal girls. Obes Res 6:262-267

25. Pintauro SJ, Nagy TR, Duthie CM, Goran MI 1996 Cross-calibration of fat and lean measurements by dual-energy x-ray absorptiometry to pig carcass analysis in the pediatric body weight range. Am J Clin Nutr 63:293-298

26. Brunton JA, Bayley HS, Atkinson SA 1993 Validation and application of dual-energy $\mathrm{x}$-ray absorptiometry to measure bone mass and body composition in small infants. Am J Clin Nutr 58:839-845

27. Ellis KJ, Shypailo RJ, Pratt JA, Pond WG 1994 Accuracy of dual-energy x-ray absorptiometry for body-composition measurements in children. Am J Clin Nutr 60:660-665

28. Chan GM 1992 Performance of dual-energy x-ray absorptiometry in evaluating bone, lean body mass, and fat in pediatric subjects. J Bone Miner Res 7:369-374

29. Hicks VL, Heyward VH, Baumgartner RN, Flores AJ, Stolarczyk LM, Wotruba EA 1993 Body composition of Native-American women estimated by dual-energy x- ray absorptiometry and hydrodensitometry. Basic Life Sci 60:89-92

30. Lohman TG, Roche AF, Martorel R (eds) 1988 Anthropometric Standardization Manual. Human Kinetics, Champaign, IL

31. Slaughter MH, Lohman TG, Boileau RA, Horswill CA, Stillman RJ, Van Loan MD, Bemben DA 1988 Skinfold equations for estimation of body fatness in children and youth. Hum Biol 60:709-723

32. Houtkooper LB, Going SB, Lohman TG, Roche AF, Van Loan M 1992 Bioelectrical impedance estimation of fat-free body mass in children and youth: a cross-validation study. J Appl Physiol 72:366-373

33. Bland J, Altman D 1986 Statistical methods for assessing agreement between two methods of clinical measurement. Lancet 1:307-310

34. Fields D, Goran M 2000 Body composition techniques and the four-compartment model in children. J Appl Physiol 89:613-620

35. Fields DA, Hunter GR, Goran MI 2000 Validation of the BOD POD with hydrostatic weighing: influence of body clothing. Int J Obes Relat Metab Disord 24:200-205

36. McCrory MA, Mole PA, Gomez TD, Dewey KG, Bernauer EM 1998 Body composition by air-displacement plethysmography by using predicted and measured thoracic gas volumes. J Appl Physiol 84:1475-1479

37. Roemmich JN, Clark PA, Weltman A, Rogol AD 1997 Alterations in growth and body composition during puberty. I. Comparing multicompartment body composition models. J Appl Physiol 83:927-935 